\title{
Tratamento cirúrgico de frenectomia lingual: Relato de caso
}

\author{
Surgical treatment of lingual frenectomy: Case report \\ Tratamiento quirúrgico de la frenectomía lingual: Reporte de caso
}

recebido: 03/04/2021 | revisado: 11/04/2021 | aceito: 05/05/2021 | publicado: 19/05/2021

\author{
Christian Recchioni ${ }^{1}$ \\ ORCID: https://orcid.org/0000-0003-0967-4530 \\ Centro Universitário Avantis, Brasil \\ E-mail: christianrecchioni@yahoo.com.br \\ Luis Augusto Leite ${ }^{2}$ \\ ORCID: https://orcid.org/0000-0002-4072-2978 \\ Centro Universitário Avantis, Brasil \\ E-mail: gtoleite@gmail.com \\ Pamela Gomes ${ }^{3}$ \\ ORCID: https://orcid.org/0000-0002-7545-5056 \\ Faculdade de Ciências Médicas do Pará, Brasil \\ Hospital Regional de Tucuruí, Brasil \\ E-mail: pamelacassia@hotmail.com \\ Augusto Soares do Prado Pellicioli ${ }^{4}$ \\ ORCID: https://orcid.org/0000-0002-9788-6172 \\ Centro Universitário Avantis, Brasil \\ E-mail: augustopellicioli@hotmail.com \\ Rafael Martins Meneghetti ${ }^{4}$ \\ ORCID: https://orcid.org/0000-0003-4632-8864 \\ Centro Universitário Avantis, Brasil \\ E-mail: rafaelmeneghetti@gmail.com \\ Ana Luiza da Silva Fernandes ${ }^{4}$ \\ ORCID: https://orcid.org/0000-0003-0866-0719 \\ Centro Universitário Avantis, Brasil \\ E-mail:ana2015fernandes@outlook.com \\ Gabriela Carvalho dos Passos ${ }^{4}$ \\ ORCID: https://orcid.org/0000-0003-4584-6248 \\ Centro Universitário Avantis, Brasil \\ E-mail:gabrielacdospassos@gmail.com
}

\begin{abstract}
Resumo
Anquiloglossia, também conhecida popularmente como “língua presa“ é uma anomalia congênita, definida como uma prega mediana localizada no dorso da língua e próximo ao assoalho bucal, que se estende até face lingual da crista alveolar. É constituído por pregas da membrana mucosa, tecido conjuntivo rico em fibras colágenas e elásticas, tecido gorduroso e fibras musculares, além de vasos sanguíneos protegidos por tecido epitelial pavimentoso estratificado. Tem a função de auxiliar na movimentação tridimensional da língua, deglutição, dicção e sucção. Nos casos de alterações congênitas, observa-se limitações dos movimentos linguais, interferências periodontais, ortodônticas, protéticas, além da socialização. A indicação cirúrgica geralmente é diagnosticada por dentistas, fonoaudiólogos e pediatras, podendo ser tratada cirurgicamente em qualquer idade através de técnicas convencionais e outras técnicas descritas na literatura, com auxílio de lâminas frias, eletrocautérios ou laser cirúrgico. O objetivo desse trabalho é relatar o caso de frenectomia lingual de um paciente do gênero masculino de 15 anos de idade.
\end{abstract}

Palavras-chave: Anquiloglossia; Anquiloglossia parcial; Língua presa.

\begin{abstract}
Ankyloglossia, also popularly known as "tongue stuck" is a congenital anomaly, defined as a median crease located on the back of the tongue and close to the buccal floor, which extends to the lingual face of the alveolar crest. It consists of folds of the mucous membrane, connective tissue rich in collagen and elastic fibers, fatty tissue and muscle fibers, in addition to blood vessels protected by stratified squamous epithelial tissue. It has the function of assisting in the three-dimensional movement of the tongue, swallowing, diction and suction. In cases of congenital alterations, there are limitations to the lingual movements, periodontal, orthodontic, prosthetic interferences, in addition to socialization. The surgical indication is usually diagnosed by dentists, speech therapists and pediatricians, and can be treated surgically at any age using conventional techniques and other techniques described in the literature, with the
\end{abstract}

\footnotetext{
${ }^{1}$ Especialista e Mestre em CTBMF, Doutorando e Professor do Centro Universitário Avantis - Uniavan - Balneário Camboriú/SC.

${ }^{2}$ Especialista em Implantodontia e Professor do Centro Universitário Avantis - Uniavan - Balneário Camboriú/SC

${ }^{3}$ Mestranda em CTBMF, acadêmica de Medicina Facimpa Hospital Regional de Tucuruí,/PA

${ }^{4}$ Acadêmico de Odontologia do Centro Universitário Avantis - Uniavan - Balneário Camboriú/SC
} 
aid of cold blades, electrocautery or surgical laser. The objective of this work is to report the case of lingual frenectomy in a 15-year-old male patient.

Keywords: Ankyloglossia; Partial ankyloglossia; Stuck tongue.

\section{Resumen}

La anquiloglosia, también conocida popularmente como "lengua pegada", es una anomalía congénita, definida como un pliegue mediano ubicado en la parte posterior de la lengua y cerca del piso bucal, que se extiende hasta la cara lingual de la cresta alveolar. Está formado por pliegues de la mucosa, tejido conectivo rico en colágeno y fibras elásticas, tejido graso y fibras musculares, además de vasos sanguíneos protegidos por tejido epitelial escamoso estratificado. Tiene la función de asistir en el movimiento tridimensional de la lengua, deglución, dicción y succión. En casos de alteraciones congénitas, existen limitaciones a los movimientos linguales, interferencias periodontales, ortodóncicas, protésicas, además de la socialización. La indicación quirúrgica suele ser diagnosticada por odontólogos, logopedas y pediatras, pudiendo tratarse quirúrgicamente a cualquier edad mediante técnicas convencionales y otras técnicas descritas en la literatura, con ayuda de cuchillas frías, electrocauterio o láser quirúrgico. El objetivo de este trabajo es reportar el caso de frenectomía lingual en un paciente masculino de 15 años. Palabras clave: Anquiloglosia; Anquiloglosia parcial; Lengua presa.

\section{Introdução}

O freio é uma estrutura anatômica que exerce o papel de "fixar algumas partes anatômicas da boca" (Leonardi, 2020). A anquiloglossia, também conhecida popularmente como "língua presa" é uma anomalia congênita, definida como uma prega mediana localizada no dorso da língua, próximo ao assoalho bucal, que se estende até face lingual da crista alveolar.

Histologicamente, são constituídos de epitélio pavimentoso estratificado queratinizado na área da gengiva inserida e não queratinizado na porção vestibular (Isac, 2018), que apresenta pregas da membrana mucosa, tecido conjuntivo composto rico em fibras colágenas e elásticas, tecido gorduroso e fibras musculares (fibras superiores do músculo genioglosso), além de vasos sanguíneos protegidos por tecido epitelial pavimentoso do tipo estratificado.

Em relação ao seu tamanho, freios linguais apresentam quartos principais subtipos: classe I (entre 12 a 16mm); classe II (entre 8 a 11mm); classe III (entre 3 a 7mm); e classe IV (menos de 2mm), (Barot et. al.,2014; Ghaheri et. al.,2018; Recchioni et. al., 2019).

Segundo Muranaka (2018), apud Araujo et al (2015), freios linguais podem sofrer alterações, quanto a sua inserção (freio curto, curto com inserção anteriorizada), além do tamanho, volume e constituição. Alterações na movimentação total ou parcial da lingual, fonética e dicção são algumas das principais consequências originadas pela inserção anormal do freio lingual, assim como, alterações periodontais, ortodônticas e protéticas, exemplificadas pela dificuldade de higienização bucal, instabilidade e ausência de retenção de próteses, além de problemas psicossociais pela dificuldade de expressão (Brito et. al., 2008; Ghaheri et. al.,2018; Ferreira LSR, et al., 2018; Marchesan IQ, 2010). Problemas na dicção, provém de distorções fonéticas mais comuns ("s" e "z"); sialorreia; movimentação excessiva da mandíbula (lateralização e anteriorização) para compensação e adaptação à limitação originada da anquiloglossia, que possa causar imprecisão da fala (Gonçalves et. al., 2006; Recchioni et. al., 2019; Ferreira et al.,2018).

Diante dessas irregularidades, a frenectomia têm sido o procedimento cirúrgico mais indicado para tratar essas alterações. Adicionalmente esse procedimento objetiva a remoção do freio lingual, permitindo movimentações adequadas da língua, necessárias às atividades funcionais (Silva,2018; apud Kina et. al., 2005; apud Almeida,2006). Segundo Izolani Neto et. al., (2014) a frenectomia poderá ser realizada através de várias técnicas cirúrgicas, conforme descrito na literatura, como: Archer, Archer Modificada; Chelotti; Wassmund; Mead; Howe e laser cirúrgico de corte e etc. (Silva,2018).

A técnica mais comum e convencional, é realizada com auxílio da lâmina fria de bisturi; eletrocautério ou bisturi elétrico; ou laser cirúrgico de corte, todas, objetivando a remoção das fibras que unem o centro da face interna da mandíbula com a face inferior da língua, permitindo movimentação tridimensional da mesma, além de avaliações e terapias com fonoaudiólogos para reestabelecimento da fala e fisiologia normal (Recchioni et. al.,2019).

Já a frenotomia ou frenulotomia (secção do freio lingual) é indicada ainda nos primeiros dias de vida, evitando dificuldades 
no processo de amamentação (sucção do leite materno), ou mesmo a frenectomia (remoção completa do freio lingual) para crianças pouco maiores e adolescentes para evitar alterações na dicção, transtornos psicológicos e bulling (RECCHIONI et. al.,2019).

\section{Metodologia}

A metodologia utilizada foi um "relato de caso", a partir da descrição e análise do tratamento cirúrgico da Anquiloglossia Lingual. (Pereira A. S. et al., 2018). O objetivo do relato de caso foi apresentar a descrição da anquiloglossia possibilitando um diagnóstico, intervenção cirúrgica e tratamento incluindo de tratamento incluindo as técnicas adotadas de forma mais detalhada, completa, exaustiva, justificando a sua aplicabilidade (Yin,2015). Autores como Estrela (2015), cita a utilização no relato de caso clínico, bastante comum na área da saúde, por via qualitativa e quantitativa.

Para a realização deste artigo, foi realizado uma busca por meio da plataforma de pesquisa: Scielo, Ebesco, Google Acadêmico e Pubmed, acerca do termo anquiloglossia, entre os períodos de 2015 e 2021, resultando na seleção de oito artigos. Portanto o artigo abordou a experiência clínica particular ao descrever: os freios linguais, constituição histológica, tipos de freios e suas devidas classificações e possíveis complicações (Perreira A. S. et al., 2018). Essa contextualização de informações quantitativos e qualitativos podem complementarem e fomentarem uma maior compreensão do assunto e de acordo com a entrevista do paciente durante a anamnese, associada ao embasamento teórico e prático através da condução do passo a passo (Yin, 2015; Perreira A. S. et al., 2018). O artigo foi um fenômeno relevante e apresenta interesse para os odontólogos ou a sociedade; e nos permite algumas reflexões a cerca da anquiloglossia, em relação sobre a idade tardia deste paciente a ser encaminhado para resolução do caso. Cabe chamar atenção para a limitação fonética desse paciente e a integração em sociedade, o diagnóstico tardio por desconhecimento familiar ou negligência e imprudência de odontólogos. (Perreira A.S. et al.,2018).

O projeto foi submetido à Plataforma Brasil. O estudo está em consonância com os critérios estabelecidos pela Resolução 466/2012 do Conselho Nacional de Saúde, que fundamenta o direcionamento ético recomendado para pesquisa envolvendo seres humanos de forma direta ou indireta, individual ou coletiva. Esta resolução aborda, ainda, a promoção do respeito ao participante, concedendo-lhe dignidade e autonomia (BRASIL, 2012).

Neste sentido, através dos TCLE o participante está ciente dos objetivos dessa pesquisa, riscos e benefícios do relato de caso. O paciente assinou o mesmo, sendo garantido o anonimato por meio do processo de codificação, permitindo que a verdadeira identidade do participante da pesquisa.

\section{Relato de Caso}

Paciente M. W. L. A. S, gênero masculino, 15 anos, foi encaminhado pelo ortodontista para a Clínica de Cirurgia Bucomaxilofacial da Faculdade Avantis - Uniavan - Balneário Camboriú - SC, orientado, corado, afebril e deambulando, queixando de alterações fonéticas, dificuldades na movimentação lingual e vergonha ao se expressar em público. À anamnese, a progenitora dele negou qualquer tipo de alteração de ordem sistêmica que pudesse interferir no tratamento, além do preenchimento do Termo de Consentimento Livre Esclarecido e autorização do uso de imagens para meios didáticos e científicos conforme os protocolos éticos. Ao exame clínico (oroscopia) observou-se dificuldades de movimentação parcial e extrusão da língua, além de alterações na fonética. Para o procedimento cirúrgico, foi realizado o protocolo de cirurgia segura para confirmação de dados pessoais do paciente e alterações de ordem sistêmica, além da confirmação do procedimento realizado e apresentação da equipe, objetivando evitar acidentes e complicações; seguido do malinúvio (antissepsia das unhas, mãos e antebraços), paramentação, montagem dos campos e protocolos de biossegurança; antissepsia intra e extrabucal com a pinça de Pean, respectivamente com solução de clorexidina $0,12 \%$ e $2 \%$; anestesia com a seringa Carpule em região de ápice lingual com lidocaína a 2\% e felipressina 1:100.000, objetivando suspensão da língua para melhor visualização do campo operatório e 
aplicação adequada da técnica; seguido da anestesia local com punção próximo ao freio lingual de forma bilateral (não diretamente sobre o freio lingual para não "mascarar" a delimitação e demarcação da incisão cirúrgica); técnica da "pinçagem simples" com uma única pinça hemostática tipo Mosquito, aprisionada acima da glândula sublingual, evitando lesão da referida glândula; incisão com cabo de bisturi Paker $n^{\circ} 3$ e lâmina de bisturi nº 15 , seguindo a anatomia referencial do freio lingual e atento às regiões anatômicas nobres, como artérias sublinguais bilateralmente e ducto sublingual); após a remoção (exérese) do freio lingual, foi realizada a divulsão com tesoura Íris, objetivando rompimento das fibras musculares; sutura simples com fio de Nylon 3.0 com porta-agulha Mathier e pinça dente-de-rato; além da terapêutica medicamentosa pós-operatória com Cetoprofeno 100mg de 12 em 12 horas por 3 dias e dipirona sódica 500mg de 6 em 6 horas por 2 dias; orientações pós-cirúrgicas de rotina para tal procedimento; retorno em 7 dias para remoção das suturas e avaliação pós-operatória. Após 7 dias o paciente retornou sem queixas e com movimentação tridimensional da língua normal, sendo encaminhado para o serviço de fonoaudiologia para avaliação e reestabelecimento da fisiologia normal da língua e fonética.

Figura 1. Inserção lingual (aspecto de “coraçãozinho“). Figura 2. Divulsão com tesoura Iris (aberta).

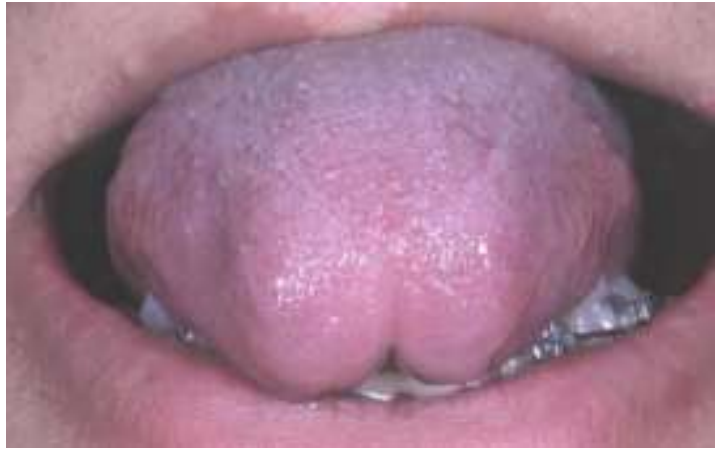

Fonte: Autores (2021).

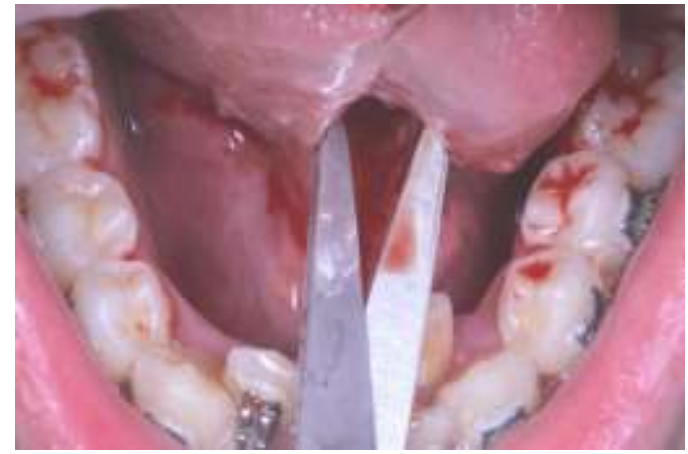

Fonte: Autores (2020).
Figura 3. Anestesia bilateral.

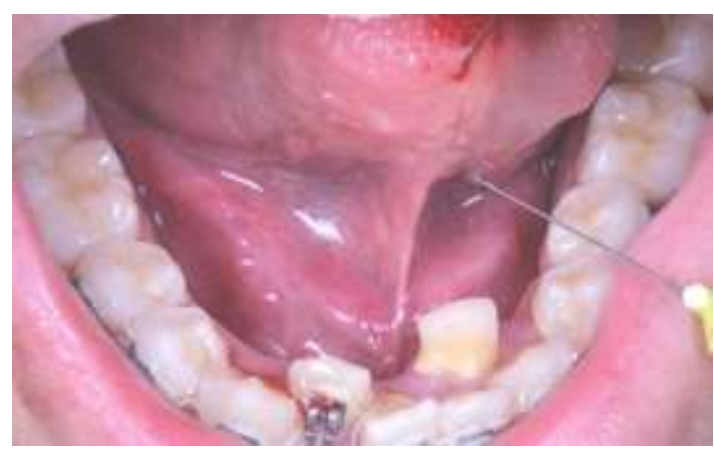

Fonte: Autores (2021).

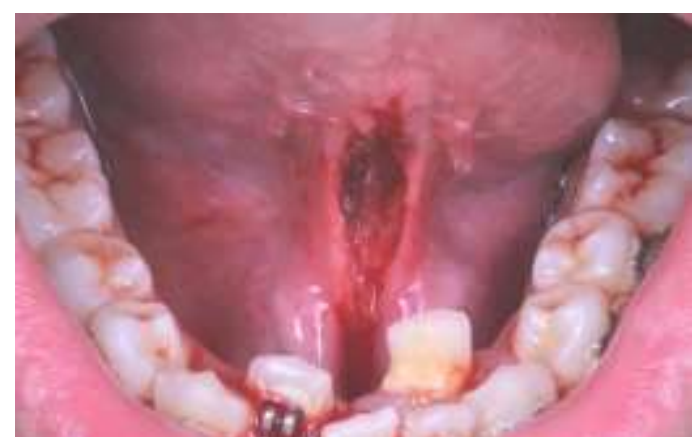

Fonte: Autores (2021). 
Figura 5. Técnica convencional da "Pinçagem simples".

Figura 6. Sutura inicial.

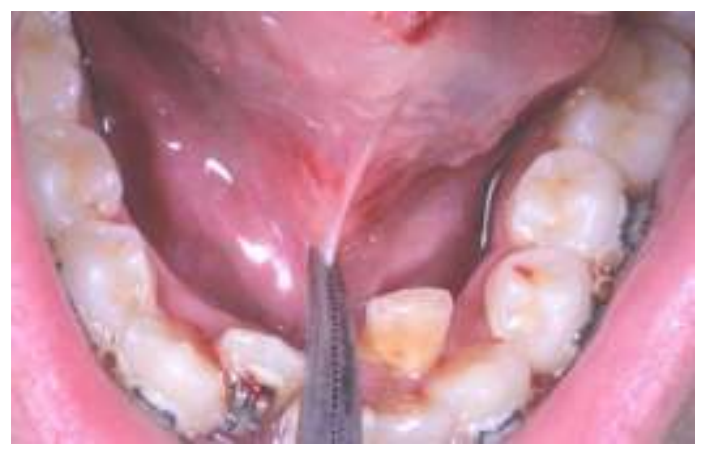

Fonte: Autores (2021).

Figura 7. Incisão com lâmina de bisturi n15.

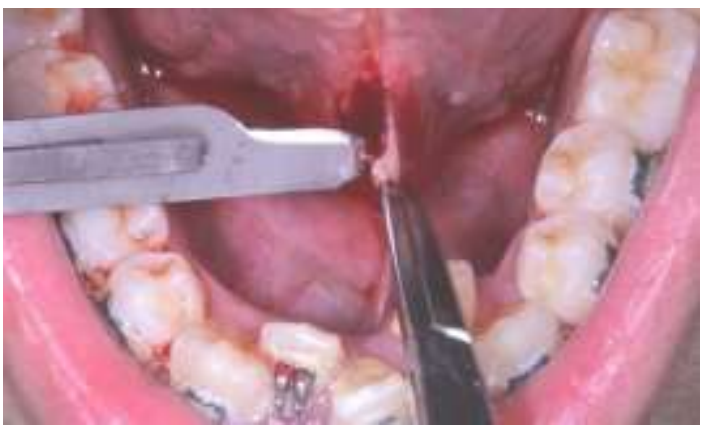

Fonte: Autores (2021)

Figura 9. Divulsão com a tesoura Iris (fechada).

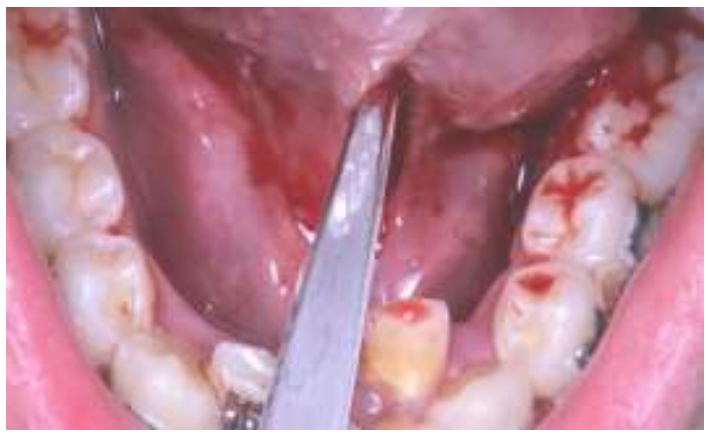

Fonte: Autores (2021)

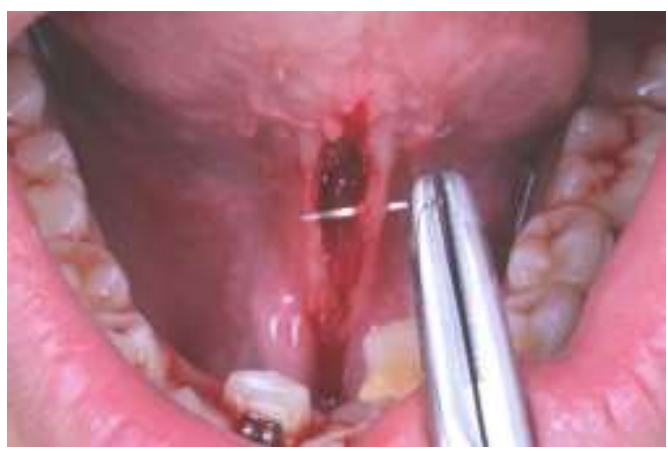

Fonte: Autores (2021).

Figura 8. Sutura final.

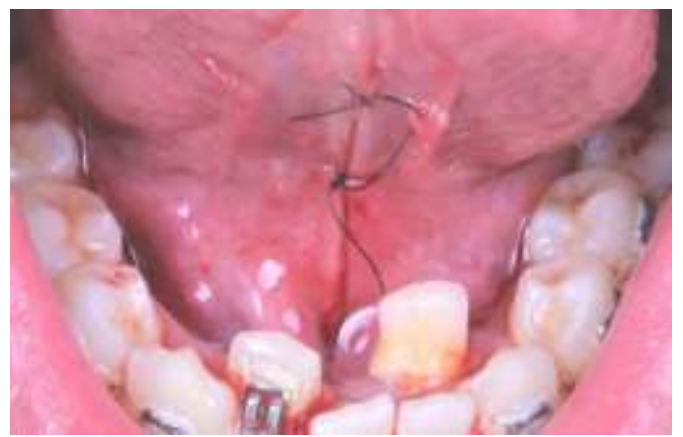

Fonte: Autores (2021).

Figura 10. Imagem de língua sem inserção.

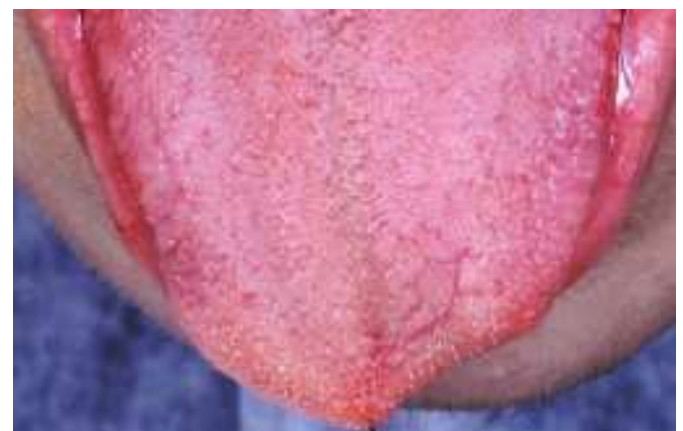

Fonte: Autores (2021).

\section{Discussão}

De acordo com Isac et. al., (2018), a língua é considerada uma estrutura muito importante, tratando-se dos músculos do corpo humano. Possui porção dividida em bucal e faríngea, fixadas por músculos ao hioide, mandíbula, processos estiloides, palato mole e parede da faringe. Possui raiz, ápice, dorso curvo e face inferior, com formato de cone posicionado no sentido sagital e plana no sentido craniocaudal. A mucosa dorsal é coberta por inúmeras papilas, e as fibras musculares intrínsecas 
apresentam um complexo de faixas longitudinais, transversais, verticais e horizontais, possibilitando mobilidade tridimensional. O dorso da língua geralmente é convexo em todas as direções quando em repouso.

Segundo Muranaka et. al., (2018), o freio lingual apresenta fibras elásticas, o que transforma a língua em um órgão ímpar à sua complexidade. Há órgãos nobres que compreendem tal anatomia, como ductos salivares de Wharton e Rivinus, nervo lingual e vasos sublinguais. Portanto, o freio lingual pode ser considerado um tecido embriológico remanescente no plano sagital, entre o ventre da língua e o pavimento bucal. Dixon et. al., (2018) acrescenta que o freio lingual pode interferir nos movimentos linguais, principalmente quando o seu local de inserção é muito próximo da margem gengival inferior, ou mesmo, em casos que ele é curto.

Segundo Izolani Neto et. al., (2014) o freio lingual é considerado uma patologia, quando há anomalias no tamanho, volume, constituição e/ou inserções que determinam condições funcionais desfavoráveis. O termo anquiloglossia é definido na literatura, como um freio lingual anormal, seja curto, ou quando há fusão da língua no assoalho bucal, conhecida popularmente como "Língua presa“. Para Muldoon et. al., (2017), a anquiloglossia pode interferir no processo fisiológico de amamentação (sucção do leite materno), em recém-nascidos. Na infância e na adolescência, pode dificultar a higiene bucal, além de alterações na dicção, movimentos tridimensionais da língua e alterações psicossociais caracterizado por bullying (Recchioni et. al.,2019). Os motivos mais comuns pela procura da frenectomia são as alterações na dicção, alterações mastigatórias e deglutição (Murakana et. al., 2018; Silva et. al., 2018; Isac, 2018; Cavenessi,2019).

É difícil estabelecer uma idade específica para a realização da frenectomia, pois alguns autores defendem que a melhor época para a cirurgia é anteriormente ao desenvolvimento da fala, evitando distúrbios da dicção e dificuldades no processo fisiológico de amamentação durante a fase de lactação (Gomes et. al.,2015), portanto, outros autores defendem que a frenectomia só é indicada quando há alterações evidentes, que justifique a cirurgia (geralmente após 4 anos de idade). Para pacientes adultos, a frenectomia lingual é indicada principalmente, quando há alterações na dicção e psicossociais (Rego,2017).

A técnica convencional apresenta vantagens quando comparada às técnicas com bisturi elétrico e laser cirúrgico de corte,custo acessível, e como desvantagem reparação tecidual mais lenta, risco de edema, dor pós-operatório, hemorragias e infecções, exigindo maior cuidado trans e pós-operatório (Silva et. al.,2018). O uso de bisturi elétrico e laser cirúrgico de corte, cada uma com suas vantagens e desvantagens. O bisturi elétrico possui vantagens de hemostasia instantânea; melhor visualização do sítio cirúrgico; precisão do corte e tempo reduzido de procedimento; menor edema e dor pós-operatório; esterilização da ferida cirúrgica; e custo um pouco mais elevado do que a técnica convencional, e como desvantagem, o fumo cirúrgico que pode acarretar queimaduras; já o laser cirúrgico de corte apresenta hemostasia instantânea; melhor visualização do sítio cirúrgico; precisão do corte e tempo reduzido de procedimento; menor edema e dor pós-operatório; esterilização da ferida cirúrgica; dispensa uso de suturas; além da excelente reparação tecidual e conforto pós-operatório, no entanto a principal desvantagem é o custo bastante elevado do aparelho de laser, que reflete no aumento do valor do procedimento (Silva et. al.,2018).

Segundo Izolani Neto et. al, (2014) a frenectomia é o procedimento pode ser realizado através de várias técnicas cirúrgicas, conforme descrito na literatura, como: Archer, Archer Modificada; Chelotti; Wassmund; Mead; Howe e laser cirúrgico de corte e etc (SILVA,2018). A técnica mais comum e convencional, é realizada com auxílio da lâmina fria de bisturi; eletrocautério ou bisturi elétrico; ou laser cirúrgico de corte, todas, objetivando a remoção das fibras que unem o centro da face interna da mandíbula com a face inferior da língua, permitindo movimentação tridimensional da mesma, além de avaliações e terapias com profissionais fonoaudiólogos para reestabelecimento da fala e fisiologia normal (Recchioni et. al.,2019).

\section{Conclusão}

O diagnóstico precoce da anquiloglossia é fundamental para evitar alterações da dicção, amamentação fisiológica, alterações psicossociais, além de outras alterações da cavidade bucal. Inúmeras técnicas foram propostas na literatura para 
procedimentos cirúrgicos de frenectomias, cada um com suas vantagens e desvantagens, mas é fundamental que o profissional tenha domínio técnico para a indicação correta de forma individualizada, além dos custos e condições financeiras do paciente. Para realização de frenectomias em geral, recomenda-se treinamentos técnicos, a fim de evitar acidentes e complicações trans e pós-operatórias, principalmente lesão de estruturas nobres da região (lesão de artérias e ductos).

\section{Referências}

Barot, V. J.et al. (2014). Laser: The Torch of freedom for anquiloglossia. Indian J Plast Surg.47 (3).418-22.

Brito, S. F. et al. (2008). Frênulo Lingual: classificação e conduta segundo ótica fonoaudiológica, odontológica e otorrinolaringológica. Rev. Cefac, São Paulo, (10): 9 .

Canevassi, Pmbt. (2019). Movimentos mandibulares durante a fala, pré e pós frenectomia lingual. Tese (Pós-graduação em Saúde da comunicação Humana), centro de ciências da saúde, universidade federal de Pernambuco. Recife.

Estrela, C. (2018). Metodologia Científica: Ciência, Ensino, Pesquisa. Editora Artes Médicas.

Ferreira lsr, et al. (2018). Anquiloglossia: revisão de literatura. Caderno de Graduação-Ciências Biológicas e da Saúde. UNIT-PERNAMBUCO, 3(3).93.

Ghaheri, B. A.et al.(2018). Revision Lingual Frenectomy improves patient reported breastfedinge outcomes: a prospective cohost study.J Hum Lact.

Gomes, E. et al (2015). Freio lingual: Abordagem clínica interdisciplinar da fonoaudiologia e odontopediatria. Ver Assoc Paul Cir Dent.

Gonçalves, C. S., ferreiro M.C.et al. (2006). Estudo da relação entre presença de Frênulo lingual curto e/ou anteriorizado e a dorsalização de [r] na articulação da fala. Rev Cefac 8 (1):56-60.

Isac, C. (2018). Frenectomia - Momento ideal para intervenção. Tese (Mestrado medicina dentária), Instituto Universitário Egas Moniz. Almada.

Izolani, N. et. al (2014). Frenectomia: revisão de literatura. Uningá Review.

Leonardi, N. (2020). A frenectomia da criança e do adulto. Relatório de estágio (Mestrado Integrado em Medicina Dentária), Instituto Universitário de Ciências da Saúde. Grande.

Marchesan, I. Q. (2010). Protocolo De Avaliação Do Frênulo Da Língua. Speech, Language, Hearing Sciences and Education Journal.12(6).977-989.

Muranaka, F. et al. (2018). Implicações das alterações morfológicas do Frênulo lingual no aparelho estomatognático.7ºJornada científica e tecnológica da Fatec de Botucatu, São Paulo.

Pereira A. S. et al. (2018). Metodologia da pesquisa científica. [free e-book]. Santa Maria/RS. Ed. UAB/NTE/UFSM.

Recchioni, C. et. al. (2019). Práticas em cirurgia Bucomaxilofacial: Cirurgias pré-protéticas. Vol. III. Editora Nativa.

Rego, Ast. (2017). Frenectomia: Momento ideal da intervenção cirúrgica. Tese (Mestrado em medicina dentária), Universidade do Porto. Porto.

Silva, Hewerton Luis. et al. (2018). Frenectomia: revisão de conceitos e técnicas cirúrgicas. Saluvista, Bauru, (37),1.

Yin, R. K. O Estudo de caso. Porto Alegre: Bookman, 2015. 